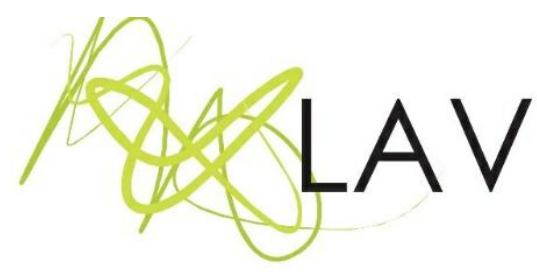

\title{
História e cultura afro-brasileira nos cursos de Licenciatura em Artes Visuais do nordeste e sul do Brasil
}

\author{
Afro-Brazilian culture and history in Visual Arts teaching degrees in the Northeast and \\ South of Brazil
}

\author{
Janine Alessandra Perini ${ }^{i}$ \\ Universidade Federal do Maranhão \\ Valéria Metroski de Alvarengaii \\ Secretaria de Estado da Educação do Paraná
}

\section{Resumo}

Esta pesquisa faz parte do "Observatório da Formação de Professores no âmbito do Ensino de Arte: estudos comparados entre Brasil e Argentina". O objetivo principal é verificar se os cursos de Licenciatura em Artes Visuais das Regiões Nordeste e Sul do Brasil, com categoria administrativa pública e oferta na modalidade presencial, oferecem ou não disciplinas específicas sobre a história e a cultura afro-brasileira. De cunho bibliográfico e de análise documental, com aporte teórico de Munanga (2019), Vázquez (2011) e Silva (2012), a pesquisa constatou que: 14 dos 27 cursos apresentam disciplinas sobre o tema; apenas um curso aborda questões regionais dentro das disciplinas analisadas; seis cursos ofertam uma disciplina para contemplar a temática afro-brasileira, junto da indígena; e algumas IES não ofertam disciplinas específicas sobre a temática, mas fazem referência a ela de modo diluído em outras disciplinas do currículo.

Palavras-chave: história e cultura afro-brasileira, artes visuais, licenciatura, matriz curricular.

\begin{abstract}
The present research is part of the project "Observatory of Teacher Training in Art Education: comparative studies between Brazil and Argentina" (Observatório da Formação de Professores no âmbito do Ensino de Arte: estudos comparados entre Brasil e Argentina). The main objective is to verify if teaching degrees in Visual Arts in the Northeast and South regions of Brazil, with public administrative category and offered in presential modality, offer specific subjects regarding Afro-Brazilian culture and history. With bibliographical approach and documental analysis, with theoretical contribution of Munanga (2019), Vásquez (2011) and Silva (2012), it was found that 14 of the 27 courses present subjects regarding the theme; only one course approaches regional matters on the subjects analyzed; six courses offer a subject to contemplate the Afro-Brazilian thematic, together with the native Indian thematic; and a number of higher education institutions do not offer specific subjects about the thematic, but reference them in a diluted manner in other courses in their curriculum.
\end{abstract}

Keywords: Afro-Brazilian culture and history, visual arts, teaching degree, curriculum. 


\section{Resumen}

Esta investigación es parte del Observatorio de la Formación Docente en el ámbito de la Enseñanza del Arte: estudios comparativos entre Brasil y Argentina. El objetivo principal es verificar si los cursos de Licenciatura en Artes Visuales en las regiones Noreste y Sur de Brasil, con categoría administrativa pública y ofrecidos en la modalidad presencial, si ofrecen o no disciplinas específicas sobre la historia y la cultura afrobrasileña. Análisis bibliográfico y documental, con apoyo teórico de Munanga (2019), Vázquez (2011) y Silva (2012), la investigación encontró que 14 de los 27 cursos presentan disciplinas sobre el tema, que solo un curso aborda temas regionales dentro de las disciplinas analizadas, que seis cursos ofrecen una disciplina para contemplar la temática afrobrasileña, junto con la indígena y que algunas IES, que no ofrecen disciplinas específicas sobre la temática, hacen referencia a ella de manera diluida en otras materias del currículo.

Palabras clave: Historia y Cultura Afrobrasileña, Artes Visuales, Licenciatura, Matriz Curricular.

\section{Introdução}

Este artigo é fruto da pesquisa realizada pelo projeto em rede do Observatório da Formação de Professores no âmbito do Ensino de Arte: estudos comparados entre Brasil e Argentina (OFPEA/BRARG). Iniciado em 2011, com a coordenação da Profa. Dra. Maria Cristina da Rosa Fonseca da Silva, tem a finalidade de investigar o processo de formação de professores no campo do ensino das artes, em especial nas Artes Visuais, com a pretensão de produzir material bibliográfico que auxilie pesquisadores da área. Visando contribuir com esse projeto, nosso artigo tem por intuito coletar dados que permitam comparar os cursos públicos, na modalidade presencial de Licenciatura em Artes Visuais das Regiões Sul e Nordeste do Brasil com foco na arte, na história e na cultura afrobrasileira.

O termo afro-brasileiro é constituído pela influência do africano no Brasil, desde o período colonial até os dias atuais. Estudar a arte, a história e a cultura desse povo é entender as questões artísticas, históricas e socioculturais que unem Brasil e África. É refletir sobre as questões de raça, gênero e classe, valorizando a pessoa negra, desconstruindo estereótipos e conhecendo as manifestações artísticas e culturais produzidas por esse grupo étnico.

Dessa forma, apontamos que a arte negra no Brasil começa no período escravagista, a partir da vinda forçada dos africanos ao nosso país. Munanga (2019) aponta que a arte africana só foi recriada aqui parcialmente, porque a totalidade da estrutura social, política, econômica e religiosa não foram as mesmas em função de suas novas condições de vida. O autor comenta que muitas das artes africanas utilitárias e funcionais não foram recriadas no Brasil por perderem seu significado, apesar de sua presença na memória coletiva negra. Para o autor, as formas artísticas plásticas africanas e o 
surgimento da linguagem plástica afro-brasileira se dão por meio do sincretismo religioso entre santos católicos e orixás, devido à forte repressão ideológica e política. Assim, para ele, a primeira forma de arte plástica afro-brasileira, propriamente dita, é uma arte ritual, religiosa, comunitária e utilitária, mas depois seus artistas saem do anonimato e começam a produzir uma arte não étnica, com projeção na linguagem plástica universal, embora conservando vínculos identitários com suas raízes. Por isso, a arte afro-brasileira tornouse uma das expressões da identidade brasileira. Para Munanga, qualificá-la de

[...] arte negra no Brasil seria cair num certo biologismo. Seria excluir dela todos os artistas que, independentemente de sua origem étnica, participam dela, por opção político-ideológica, religiosa, ou simplesmente por emoção estética no sentido universal da palavra (MUNANGA, 2019, p. 15).

É a partir dessa noção mais ampla da arte afro-brasileira que encontramos relevância em levá-la para a sala de aula. Portanto, a arte é aqui vista como um fenômeno social, pois por meio dela o ser humano:

[...] como ser particular, histórico, se universaliza, mas não no plano de uma universalidade abstrata, impessoal e desumanizada; ao contrário, graças à arte, o homem enriquece seu universo humano, salva e faz perdurar o que tem de ser concreto e resiste a toda desumanização (VÁZQUEZ, 2011, p. 109).

Para o autor, a arte parte da particularidade histórica, social e de classe do artista, mas se universaliza criando um mundo humano ou humanizado. Pensando nessa contextualização da arte, este artigo, dividido em três partes, analisa os cursos de Licenciatura em Artes Visuais, trazendo a arte e a cultura afro-brasileira como forma de conhecimento, como processo histórico e social. Primeiramente, apresentamos a Lei no $10.639 / 2003$ e a Lei no $11.645 / 2008$, as quais tratam sobre a obrigatoriedade do ensino da história e da cultura afro-brasileira nos estabelecimentos de Ensino Fundamental e Médio, oficiais e particulares. Em seguida, contemplamos os cursos de Licenciatura em Artes Visuais da Região Nordeste e Sul do Brasil. Por fim, fazemos uma análise das ementas das disciplinas com foco na arte, na história e na cultura afro-brasileira.

\section{História e cultura afro-brasileira: entre a Lei no $10.639 / 2003$ e a Lei no $11.645 / 2008$}

A história e a cultura afro-brasileira foram sendo construídas no Brasil por meio de muita luta e muitas conquistas. Perini (2020) aponta que, pelo Decreto no 1.331 , de 17 de fevereiro de 1854, adultos negros não eram admitidos em escolas públicas do Brasil e que a instrução para eles dependia da disponibilidade de professores. Além disso, o Decreto $\mathrm{n}^{\circ}$ 
7.031-A, de 6 de setembro de 1878, declarava que os negros só podiam estudar no período noturno.

Para a autora, essas e outras estratégias foram montadas no sentido de impedir o acesso pleno dessa população aos bancos escolares, às academias de artes visuais, artes cênicas, dança e música. Ela lembra que mesmo com o fim da escravidão, com a Lei áurea de 13 de maio de 1888, o Brasil é palco por séculos de lutas por direitos políticos e sociais dos povos negros. Ademais, as conquistas dos movimentos sociais não aconteceram pacificamente. Se hoje temos uma lei que legitima conteúdos sobre a história e a cultura afro-brasileira na Educação Básica, isso ocorreu por um processo de inclusão e exclusão dentro da história da educação, com influências econômicas, sociais e culturais.

Perini (2012) reflete sobre as dinâmicas das relações sociais dos alunos negros e afirma que "[é] importante que o aluno afro-brasileiro esteja consciente de que, se ele possui fragilidades, isso foi acumulado historicamente por uma educação que negou seu acesso aos bens culturais de seu povo" (PERINI, 2012, p. 32). Assim, é necessário o resgate da história e da cultura africana e afro-brasileira nas escolas, valorizando e desmistificando estereótipos, diminuindo, assim, a discriminação e a marginalização do negro.

A obrigatoriedade do ensino da História e da Cultura Afro-brasileira na educação básica é fruto de muitas lutas do movimento negro. A Lei no 10.639/2003 faz parte das ações afirmativas de combate ao racismo e à discriminação racial, e modifica a Lei de Diretrizes e Bases da Educação Nacional (LDB) no 9.394/1996, acrescentando os Artigos 26-A e 79-B:

Art. 26-A. Nos estabelecimentos de ensino fundamental e médio, oficiais e particulares, torna-se obrigatório o ensino sobre História e Cultura Afro-Brasileira.

$\S 1$ ㅇ O conteúdo programático a que se refere o caput deste artigo incluirá o estudo da História da Africa e dos Africanos, a luta dos negros no Brasil, a cultura negra brasileira e o negro na formação da sociedade nacional, resgatando a contribuição do povo negro nas áreas social, econômica e política pertinentes à História do Brasil.

$\S 2$ 2o Os conteúdos referentes à História e Cultura Afro-Brasileira serão ministrados no âmbito de todo o currículo escolar, em especial nas áreas de Educação Artística ${ }^{1}$ e de Literatura e História Brasileira.

Art. 79-B. O calendário escolar incluirá o dia 20 de novembro como 'Dia Nacional da Consciência Negra' (BRASIL, 2003).

\footnotetext{
${ }^{1}$ A LDB no 9.394/96 alterou a nomenclatura da disciplina/componente curricular para 'Arte', mas nessa lei, assim como na Lei no 11.645/2008, ainda consta a denominação antiga 'Educação Artística'.
} 
A lei aborda que a história da África e dos africanos deve fazer parte dos conteúdos ministrados, como também a luta dos negros no Brasil, a cultura negra brasileira e o negro na formação da sociedade nacional, resgatando a contribuição do povo negro nas áreas social, econômica e política. Ela também afirma que esses conteúdos devem ser ministrados no âmbito de todo o currículo escolar, em especial nas áreas de Artes, Literatura e História.

Em 18 de maio de 2004, o Ministério da Educação homologou as Diretrizes Curriculares Nacionais para a educação das relações étnico-raciais e para o ensino de história e cultura afro-brasileira e africana ${ }^{2}$, que regulamentam e fundamentam a inserção da Lei no 10.639/2003. Essas diretrizes fazem parte de políticas de ações afirmativas, que visam reparar, reconhecer e valorizar a história, a cultura e a identidade da população afrodescendente. No que se refere às Diretrizes supracitadas, tratam-se de uma:

[...] política curricular, fundada em dimensões históricas, sociais, antropológicas oriundas da realidade brasileira, e busca combater o racismo e as discriminações que atingem particularmente os negros. Nesta perspectiva, propõe a divulgação e produção de conhecimentos, a formação de atitudes, posturas e valores que eduquem cidadãos orgulhosos de seu pertencimento étnico-racial descendentes de africanos, povos indígenas, descendentes de europeus, de asiáticos - para interagirem na construção de uma nação democrática, em que todos, igualmente, tenham seus direitos garantidos e sua identidade valorizada (BRASIL, 2004, p. 10).

Esse documento visa o direito de todos os cidadãos brasileiros, por uma escola e um ensino de qualidade, em que os professores formados em diferentes áreas de conhecimentos lidam com as tensas relações produzidas pelo racismo e pelas discriminações. Anos depois, sentindo-se também a necessidade da inclusão dos povos indígenas ${ }^{3}$, foi criada a Lei $n^{\circ} 11.645 / 2008$ que determina: "[...] nos estabelecimentos de ensino fundamental e de ensino médio, públicos e privados, torna-se obrigatório o estudo da história e cultura afro-brasileira e indígena" (BRASIL, 2008), ou seja, são acrescentadas a história e a cultura indígena. Em seu primeiro parágrafo, a lei traz uma breve explicação:

$\S 1^{\circ} \mathrm{O}$ conteúdo programático a que se refere este artigo incluirá diversos aspectos da história e da cultura que caracterizam a formação da população brasileira, a partir desses dois grupos

\footnotetext{
${ }^{2}$ A constituição de políticas públicas educacionais voltadas às relações étnico-raciais tem por objetivo atender "a demanda por reparações [visando] que o Estado e a sociedade tomem medidas para ressarcir os descendentes de africanos negros, dos danos psicológicos, materiais, sociais, políticos e educacionais sofridos sob o regime escravista, bem como em virtude das políticas explícitas ou tácitas de branqueamento da população, de manutenção de privilégios exclusivos para grupos com poder de governar e de influir na formulação de políticas, no pós-abolição. Visa também a que tais medidas se concretizem em iniciativas de combate ao racismo e a toda sorte de discriminações" (BRASIL, 2004, p. 11).

${ }^{3}$ Embora a Lei $n^{\circ} 10.639 / 2003$ tenha sido revogada, "o movimento negro continua utilizando-a em separado por entender que, ao misturar as duas demandas em uma única lei, o tema da educação afro-brasileira perde a força" (ALVARENGA, 2015, p. 102).
} 
étnicos, tais como o estudo da história da África e dos africanos, a luta dos negros e dos povos indígenas no Brasil, a cultura negra e indígena brasileira e o negro e o índio na formação da sociedade nacional, resgatando as suas contribuições nas áreas social, econômica e política, pertinentes à história do Brasil (BRASIL, 2008).

No tocante à legislação sobre as áreas prioritárias que devem abordar o assunto, no segundo parágrafo da Lei no 11.645/2008, aparece que "[...] os conteúdos referentes à história e à cultura afro-brasileira e dos povos indígenas brasileiros serão ministrados no âmbito de todo o currículo escolar, em especial nas áreas de educação artística e de literatura e história brasileira" (BRASIL, 2008). Cabe ressaltar que embora a LDB no 9.394/96 tenha alterado a nomenclatura do componente curricular para Arte e especificado o que deve ser compreendido por essa palavra (Música, Dança, Teatro e Artes Visuais ${ }^{4}$ ), a lei de 2008 ainda utilizou a denominação antiga 'Educação Artística'.

Apesar dessas leis não tratarem de uma alteração nos cursos de Licenciatura, mas sim de conteúdos previstos para a Educação Básica, precisamos considerar que os cursos de formação de professores ${ }^{5}$ têm como prioridade formar docentes para atuar nesse nível de ensino. Sendo assim, os cursos de Licenciatura devem fornecer subsídios para o futuro professor abordar esse tema nas diversas etapas da educação básica. Perini (2012) lembra que, além de instrumentalizar os professores com o conhecimento da história e da cultura africana e afro-brasileira, é necessário trabalhar a formação política do professor, suas concepções sobre raça e a conscientização da existência do racismo e do preconceito no Brasil.

Em relação às pesquisas sobre a inserção de disciplinas sobre a temática da cultura afro-brasileira e indígena, Silva (2012) analisou os cursos de Licenciatura das áreas de História, Geografia, Letras, Pedagogia e Artes (com foco nas Artes Visuais), tendo por base a Lei no 11.645/2008, e constatou que, do total de 55 Instituições de Ensino Superior (IES) que ofertam cursos de Licenciatura em Artes Visuais espalhados por todo o território nacional, ofertados na modalidade presencial e EAD, contemplando as categorias público e privado, apenas duas (2) faziam menção à temática:

[...] apenas dois cursos de Graduação em Artes Visuais, no âmbito da amostra considerada, introduziram o tema. Deve-se registrar que muitos dos cursos avaliados apresentam projetos político-

\footnotetext{
${ }^{4}$ Essa especificação ocorreu por meio da Lei no 13.278/2016.

${ }^{5}$ As Diretrizes Curriculares Nacionais para a Formação Inicial e Continuada dos Profissionais do Magistério da Educação Básica (2015), no capítulo V parágrafo 20, trata sobre estrutura e currículo dos cursos de Licenciatura e prevê que haja a garantia nos currículos de "[...] conteúdos específicos da respectiva área de conhecimento ou interdisciplinares, seus fundamentos e metodologias, bem como conteúdos relacionados aos fundamentos da educação, formação na área de políticas públicas e gestão da educação, seus fundamentos e metodologias, direitos humanos, diversidades étnico-racial [...]" (BRASIL, 2015, p. 11). Vale ressaltar que esse mesmo documento aponta que as IES e os cursos de Licenciatura possuem autonomia pedagógica, devendo-se respeitar a diversidade nacional.
} 
pedagógicos aprovados em 2009 ou 2010, e, portanto, após a vigência da lei, mas não fazem menção sequer à introdução de educação para a diversidade, ou para as relações étnico-raciais, ou consideram o aporte da cultura e arte africana ou afro-brasileira em seus currículos - todos itens referentes à legislação anterior, vigente desde 2003 e 2004 (SILVA, 2012, p. 17-18).

Silva (2012) informa que algumas IES que tiveram seus cursos de Licenciatura em Artes Visuais reconhecidos a partir de 2011 inseriram disciplinas abordando a temática da história e cultura afro-brasileira, embora esse número continue muito baixo, tendo por base a amostragem.

Será que houve mudanças nesse quadro? Para respondermos a essa questão, embora com um recorte menor, realizamos um mapeamento dos cursos de duas regiões brasileiras (Nordeste e Sul) para verificarmos se eles ofertam ou não disciplinas sobre a história e a cultura afro-brasileira, tal como veremos na sequência. A escolha dessas duas regiões se deu, porque, além de residirmos e trabalharmos em estados (Maranhão e Paraná) que fazem parte da Região Nordeste e Sul do Brasil, realizamos pesquisas de Mestrado e/ou Doutorado sobre os cursos de Licenciatura em Artes Visuais, abordando a temática do artigo em tais localidades, e também de modo expandido, devido ao projeto em rede do OFPEA/BRARG, do qual somos integrantes.

\section{Cursos de Artes Visuais nas regiões Nordeste e Sul do Brasil: há oferta de disciplinas sobre a história e cultura afro-brasileira?}

A Região Nordeste conta com nove estados brasileiros (Maranhão, Piauí, Ceará, Rio Grande do Norte, Paraíba, Pernambuco, Alagoas, Sergipe, Bahia) e o Sul com apenas três (Paraná, Santa Catarina e Rio Grande do Sul). Essas duas regiões são muito distintas uma da outra em termos geográficos, políticos, culturais e econômicos. E nós nos perguntamos: Será que os cursos de Licenciatura em Artes Visuais presenciais e públicos dessas duas regiões carregam consigo essas diferenças?

No que se refere à Região Sul, dentre as Instituições de Ensino Superior (IES), que ofertam cursos de Licenciatura em Artes Visuais presenciais e públicos, o estado do Paraná dispõe de sete nas seguintes IES: Universidade Estadual do Centro-Oeste (UNICENTRO'6), Universidade Federal do Paraná (UFPR), Universidade Estadual de Londrina (UEL), Universidade Estadual de Maringá (UEM), Universidade Estadual do Paraná (UNESPAR) com dois polos, um na Faculdade de Artes do Paraná (FAP) e outro na Escola de Música e Belas Artes do Paraná (EMBAP), Universidade Estadual de Ponta Grossa (UEPG) e Instituto

\footnotetext{
${ }^{6}$ Essa IES oferta o curso de licenciatura com a nomenclatura ARTE, porém ele foi considerado na análise devido a matriz curricular ser mais direcionada para Artes Visuais.
} 
Federal do Paraná (IFPR). No estado do Rio Grande do Sul encontram-se cinco IES: Universidade Federal do Rio Grande do Sul (UFRGS), Universidade Estadual do Rio Grande do Sul (UERGS), Universidade Federal de Pelotas (UFPeL), Universidade Federal do Rio Grande (FURG) e Universidade Federal de Santa Maria (UFSM). E, no estado de Santa Catarina, encontra-se apenas um curso presencial e público: Universidade do Estado de Santa Catarina (UDESC).

Dentre essas IES, procuramos observar se há alguma disciplina que contemple em seu título a História, Cultura ou Arte Afro-Brasileira, Diversidade Étnico-Raciais ou ÉtnicoCultural. Representamos, a seguir, na Tabela 1 o resultado da pesquisa:

\begin{tabular}{|l|l|l|l|}
\hline Nome da IES & Nome da disciplina & $\begin{array}{l}\text { Ano } \\
\text { da } \\
\text { Matriz }\end{array}$ & $\begin{array}{l}\text { Obrigatória/ } \\
\text { Optativa }\end{array}$ \\
\hline UNICENTRO & Arte Africana e Afro-Brasileira & $2014^{7}$ & Obrigatória \\
\hline UFPR & Nenhuma Afrana e Afro- & $2019^{8}$ & - \\
\hline UEL & $\begin{array}{l}\text { História da Arte Africana } \\
\text { Brasileira }\end{array}$ & $\begin{array}{l}\text { Não } \\
\text { especificado }\end{array}$ \\
\hline UEM & Nenhuma & $2017^{10}$ & - \\
\hline UNESPAR II (FAP) & Nenhuma & $2017^{11}$ & - \\
\hline UNESPAR I (EMBAP) & Nenhuma & $2018^{12}$ & - \\
\hline UEPG & Nenhuma & $2015^{13}$ & - \\
\hline IFPR & $\begin{array}{l}\text { História e Cultura Afro-brasileira e } \\
\text { Indígena }\end{array}$ & $2017^{14}$ & Obrigatória \\
\hline UDESC & Arte Africana e Afro-descendente & $2019^{15}$ & Obrigatória \\
\hline
\end{tabular}

7 Matriz curricular/"currículo pleno" criada em 2014, disponível em: https://www3.unicentro.br/proen/wpcontent/uploads/sites/41/2019/02/Arte-G.pdf Acesso em: 20 jul. 2019.

8 "Estrutura curricular/disciplinas" vigentes em 2019, disponível na página do curso da IES. Disponível em: http://www.sacod.ufpr.br/portal/artes/artes-visuais-licenciatura/ Acesso em: 20 jul. 2019.

9 Grade curricular disponível na página do curso da IES (2019). Disponível em: http://www.uel.br/prograd/documentos/resolucoes/2018/resolucao_103_18.pdf Acesso em: 20 jul. 2019.

10 Currículo do curso (com data de 11/08/2017), disponível em: http://webcache.googleusercontent.com/search?q=cache:ZRTSyjmgzWAJ:www.dtp.uem.br/grade-curricularensalamento/sar200-1/at_download/file+\&cd=1\&hl=pt-BR\&ct=clnk\&gl=br. Acesso em: 10 mai. 2021.

11 Matriz curricular em 2017, disponível em: < http://webcache.googleusercontent.com/search?q=cache:jKZqO36CWcYJ:fap.curitiba2.unespar.edu.br/assunto s/graduacao/Matriz_curricular_Artes_visuais_2017_1.pdf $+\& \mathrm{~cd}=2 \& \mathrm{hl}=\mathrm{pt}-\mathrm{BR} \& \mathrm{ct}=\mathrm{clnk} \& \mathrm{gl}=\mathrm{br}>$. Acesso em: 10 mai. 2021.

12 Matriz curricular criada em 2018, disponível em: <http://www.embap.pr.gov.br/arquivos/File/a_2018/MATRIZ_2018/MATRIZ_LAV_EMBAP_2018.pdf>. Acesso em jul. 2019.

13 Matriz curricular em criada 2015, disponível em: <https://www.uepg.br/catalogo/cursos/2016/artesvisuais.pdf>. Acesso em: 20 jul. 2019.

14 Matriz curricular vigente no ano de 2017. Disponível em: http://palmas.ifpr.edu.br/wpcontent/uploads/2018/10/ARTES_VISUAIS2018.1.pdf. Acesso: 20 jul. 2019.

15 No site da IES consta "grade curricular e ementário atual", sendo assim, consideramos o ano de 2019. Disponível <https://www.udesc.br/arquivos/ceart/id_cpmenu/2571/CURSO_DE_LICENCIATURA_EM_ARTES_VISUAIS_150 00622716416_2571.pdf>. Acesso em: 20 jul. 2019. 


\begin{tabular}{|l|l|l|l|}
\hline UFRGS & $\begin{array}{l}\text { Culturas Ameríndias e Afro- } \\
\text { brasileiras no Ensino de Arte; } \\
\text { Educação e relações étnico-raciais; } \\
\text { povos indígenas, educação e escola }\end{array}$ & & Optativas \\
\hline UERGS & Nenhuma & $2018^{18}$ & - \\
\hline UFPEL & Arte e Cultura Afro-brasileira & $2011^{19}$ & Obrigatória \\
\hline FURG & Nenhuma & $2014^{20}$ & - \\
\hline UFSM & Nenhuma & $2019^{21}$ & - \\
\hline
\end{tabular}

Tabela 1: Disciplinas sobre História e Cultura Afro-Brasileira nos cursos de Artes Visuais públicos e presenciais da Região Sul

Fonte: Elaborada pelas autoras com base nos portais institucionais das IES citadas

Do total de IES analisadas (14) que oferecem o curso de Licenciatura em Artes Visuais na Região Sul do Brasil, apenas seis, de maneira direta, nos títulos das disciplinas, tratam sobre a história e cultura afro-brasileira e/ou indígena, tal como pode ser observado na Tabela 1. Vale ressaltar, ainda, que das seis IES, apenas uma oferta três disciplinas relacionadas ao tema, enquanto as outras cinco apresentam apenas uma disciplina sobre a temática. Na sequência, apresentamos o Gráfico 1, com o percentual das IES da Região Sul que ofertam ou não alguma disciplina relacionada com a temática deste artigo:

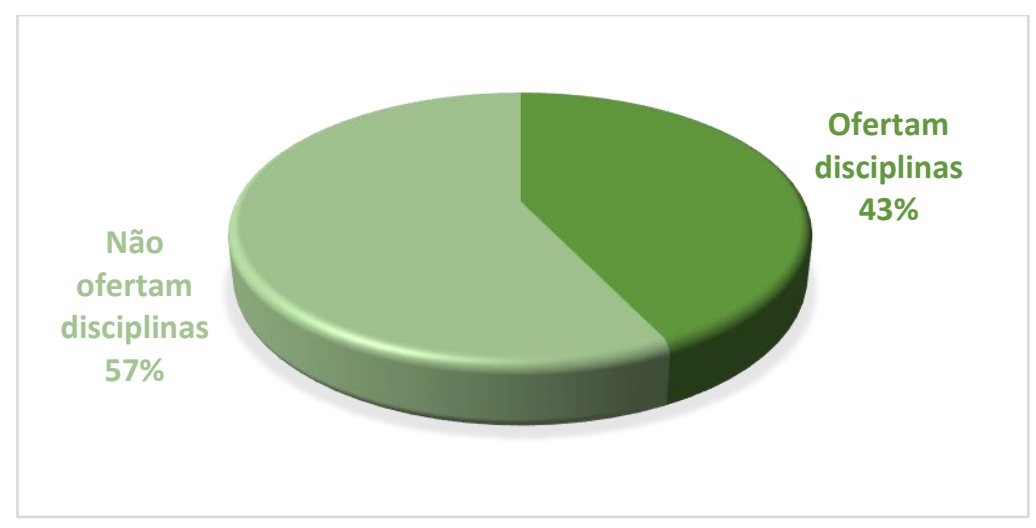

Gráfico 1: Percentual de cursos que ofertam ou não disciplina sobre a história e cultura afro-brasileira - Região Sul

Fonte: Elaborado pelas autoras com base nas matrizes das IES analisadas

16 O PPP com o ementário é de 2018 e não apresenta a ementa dessa disciplina. Disponível em: <https://www.ufrgs.br/institutodeartes/wp-content/uploads/2018/04/COMGRAD-DAV-PROJETOPEDAG\%C3\%93GICO-DA-LICENCIATURA-EM-ARTES-VISUAIS.pdf>. Acesso em: 24 nov. 2019.

17 No site da IES consta "currículo e grade curricular", consideramos o ano de 2019. Disponível em: <http://www.ufrgs.br/ufrgs/ensino/graduacao/cursos/exibeCurso?cod_curso=303>. Acesso em: 21 jul. 2019.

18 No site da IES consta "Matriz Curricular do curso de Artes Visuais - Licenciatura/2018". Disponível em: $<$ https://www.uergs.edu.br/artes-visuais-licenciatura>. Acesso em: 21 jul. 2019.

19 No site da IES consta "Fluxograma do Curso" e "Ementa das Disciplinas e Bibliografia Básica" das obrigatórias e optativas, conforme reforma curricular de 2011. Disponível em: <http://ca.ufpel.edu.br/artes/licenciatura/documentos/curriculo/fluxograma_artes_visuais_licenciatura.pdf>. Acesso em: 21 jul. 2019.

${ }^{20}$ No site da IES consta "Quadro de Sequência Lógica (QSL)", das disciplinas obrigatórias e optativas. Disponível em:

<https://sistemas.furg.br/sistemas/paginaFURG/publico/bin/cursos/tela_qsl_visual.php?cd_curso=206*632>. Acesso em: 22 jul. 2019.

${ }^{21}$ No site da IES consta "Sequência Aconselhada" das disciplinas a serem cursadas como obrigatórias, no ano corrente 2019. Disponível em: < https://www.ufsm.br/ementario/cursos/972 >. Acesso em: 10 mai. 2021. 
Alvarenga (2015) já havia constatado essas 'ausências' de disciplinas sobre a história e a cultura afro-brasileira, ao analisar as matrizes curriculares e as ementas de oito cursos de Licenciatura em Artes Visuais no Paraná. Das oito IES analisadas pela autora, $50 \%$ ofertavam uma disciplina específica sobre o tema. Essas disciplinas, quando ofertadas, em geral, apresentavam a menor carga horária se comparada às demais disciplinas do curso, além de geralmente ser apenas uma.

Se observarmos a quantidade atual de disciplinas sobre essa temática englobando a Região Sul, vemos que os dados são semelhantes, pois menos de $50 \%$ das IES analisadas $(43 \%)$ ofertam disciplinas específicas sobre a temática nos três estados dessa região. No entanto, algumas IES analisadas na Região Sul, apesar de não apresentarem disciplinas específicas sobre o tema, apresentam nas ementas de outras disciplinas alguma referência à história e à cultura afro-brasileira, tal como na UEPG:

ARTE E TÓPICOS EDUCACIONAIS. Análise crítica e discussão sobre a relação do ensino da arte com temáticas do cotidiano escolar: a educação inclusiva; a educação especial; a cultura afro-brasileira e a cultura indígena; educação ambiental; a pluralidade cultural e questões de gênero; a violência, as drogas e os conflitos escolares

POLÍTICAS PÚBLICAS E EDUCACIONAIS NO BRASIL Análise das relações entre política, educação, estado, sociedade, cidadania, trabalho e formação política do educador. Dimensões históricas, políticas, sociais, econômicas e educacionais da organização da educação brasileira. A educação a partir na Constituição Federal de 1988 e suas implicações: o Estatuto da Criança e do adolescente, a Lei de Diretrizes e Bases da Educação Nacional, o(s) Plano (os) Nacional (is) de Educação. Sistema Educacional Brasileiro. O ensino da cultura afrobrasileira e indígena na política educacional contemporânea.

HISTÓRIA DAS ARTES VISUAIS NO BRASIL História das Artes Visuais no Brasil: Pré-História; Arte Indígena; A produção das artes no Brasil Holandês. O Barroco brasileiro. A Missão Francesa e a arte Acadêmica. Das vanguardas Modernistas ao Pós-Modernismo. Arte africana e afro-brasileira. Arte Paranaense e diversidade cultural.

ESTÁGIO CURRICULAR SUPERVISIONADO EM ARTES VISUAIS II. Construção e execução de um projeto de ensino e pesquisa das Artes Visuais no Ensino Médio e Educação Especial fundamentado na teoria pedagógica crítica com docência em Artes Visuais na perspectiva da investigação-ação em espaços formais e não formais de educação. Estágio na Educação Especial e inclusão social das Artes Visuais e as questões da educação indígena, afrodescendente, educação do campo ou rural e de grupos minoritários (UEPG, 2015, p. 03-05, grifo das autoras).

Outro exemplo é a disciplina ofertada na UNESPAR II (FAP):

FUNDAMENTOS E METODOLOGIAS DO ENSINO DAS ARTES VISUAIS. Estudos dos fundamentos teórico/práticos para o ensino da Arte no Brasil e as influências internacionais assimiladas. 
Abordagens metodológicas do ensino de arte. Cultura afrobrasileira, indígena e ambiental (UNESPAR II, 2017, p. 39, grifo das autoras).

Cabe destacar que isso também pode ocorrer em outras IES que não ofertam uma disciplina específica, mas fazem menção ao assunto em outras disciplinas no currículo, sendo disciplinas mais relacionadas ao ensino das artes visuais e à história da arte brasileira. Sobre esse ponto, Alvarenga (2015) considera que, embora algumas IES não ofertem disciplinas específicas sobre o tema, não permitindo um aprofundamento da temática proposta, as menções diluídas em outras disciplinas do currículo são um indicativo de que o tema está sendo contemplado, apesar de ser de modo superficial.

Em referência aos cursos de Licenciatura em Artes Visuais no Nordeste, encontramos 13 IES que ofertam o curso na modalidade presencial e com categoria administrativa pública. O estado de Alagoas é o único da região que não oferta o curso. $\mathrm{O}$ estado da Bahia oferta em quatro IES: Universidade Federal da Bahia (UFBA), Universidade Federal do Sul da Bahia (UFSB), Universidade Federal do Oeste da Bahia (UFOB) e Universidade Federal do Vale do São Francisco (UNIVASF). No estado do Maranhão, em duas IES: Universidade Federal do Maranhão (UFMA) e Instituto Federal do Maranhão (IFMA). O estado do Ceará, também em duas IES: Instituto Federal do Ceará (IFCE), Universidade Regional do Cariri (URCA). Nos outros estados, em apenas uma IES: Universidade Federal do Piauí (UFPI), Universidade Federal do Rio Grande do Norte (UFRN), Universidade Federal da Paraíba (UFPB), Universidade Federal de Sergipe (UFS) e Universidade Federal de Pernambuco (UFPE).

Dentre essas IES, procuramos observar se há alguma disciplina que contemple em seu título a História, Cultura ou Arte Afro-Brasileira, Diversidade Étnico-Raciais ou ÉtnicoCultural. Representamos na Tabela 2 o resultado da pesquisa:

\begin{tabular}{|l|l|l|l|}
\hline $\begin{array}{c}\text { Nome da } \\
\text { IES }\end{array}$ & \multicolumn{1}{|c|}{ Nomes das disciplinas } & $\begin{array}{c}\text { Ano da } \\
\text { Matriz }\end{array}$ & $\begin{array}{c}\text { Obrigatória/ } \\
\text { Optativa }\end{array}$ \\
\hline UFMA & Arte Indígena, Africana e Afro-Brasileira. & $2016^{22}$ & Obrigatória \\
\hline IFMA & História e Cultura Africana e Afro-brasileira & $2015^{23}$ & Obrigatória \\
\hline UFPI & História e Cultura Africana e Afro-brasileira & $2018^{24}$ & Obrigatória \\
\hline IFCE & Nenhuma & $2012^{25}$ & - \\
\hline
\end{tabular}

22 Estrutura Curricular criada em 2016 do Curso Licenciatura em Artes Visuais. Disponível em: <https://sigaa.ufma.br/sigaa/public/curso/curriculo_curso.jsf>. Acesso em: 07 out. 2019.

23 Projeto Pedagógico criado em 2015 do Curso Licenciatura em Artes Visuais. Disponível em: <https://centrohistorico.ifma.edu.br/wp-content/uploads/sites/28/2019/03/Superior-artes-visuaisCompleto.pdf>. Acesso em: 07 out. 2019.

24 Estrutura Curricular criada em 2018 do Curso Licenciatura em Artes Visuais. Disponível em: <https://sigaa.ufpi.br/sigaa/public/curso/curriculo.jsf>. Acesso em: 17 jul. 2019.

25 Estrutura Curricular criada em 2012 do Curso de Licenciatura em Artes Visuais. Disponível em: https://ifce.edu.br/fortaleza/cursos/superiores/licenciatura/artes-visuais/pdf/projeto-pedagogico-artesvisuais.pdf. Acesso em: 18 mai. 2021. 


\begin{tabular}{|l|l|l|l|}
\hline URCA & História e Cultura Africana e Afro-brasileira & $2008^{26}$ & Obrigatória \\
\hline UFRN & $\begin{array}{l}\text { Direitos humanos, diversidade cultural e } \\
\text { relações étnico-raciais. }\end{array}$ & $2019^{27}$ & Optativa \\
\hline UFPB & Nenhuma & $2019^{28}$ & - \\
\hline UFPE & Arte e diversidade étnico-cultural & $2013^{29}$ & Obrigatória \\
\hline UFS & Nenhuma & $2012^{30}$ & - \\
\hline UNIVASF & Nenhuma & $2016^{31}$ & - \\
\hline UFBA & Nenhuma & $2009^{32}$ & - \\
\hline UFSB & $\begin{array}{l}\text { Educação e Relações Ético-Raciais; } \\
\text { Estéticas negrodescendentes }\end{array}$ & $2016^{33}$ & $\begin{array}{l}\text { Obrigatória } \\
\text { Optativa }\end{array}$ \\
\hline UFBO & História e Cultura Indígena e Afro-brasileira & $2018^{34}$ & Optativa \\
\hline
\end{tabular}

Tabela 2: Disciplinas sobre História e Cultura Afro-brasileira nos cursos de Artes Visuais na Região Nordeste

Fonte: Elaborada pelas autoras com base nos portais institucionais das IES

De 13 cursos de Licenciatura em Artes Visuais da Região Nordeste, oito ofertam disciplinas, tanto obrigatórias quanto optativas, sobre a história e a cultura afro-brasileira de modo explícito nas matrizes curriculares. Podemos observar melhor esse percentual a partir do Gráfico 2:

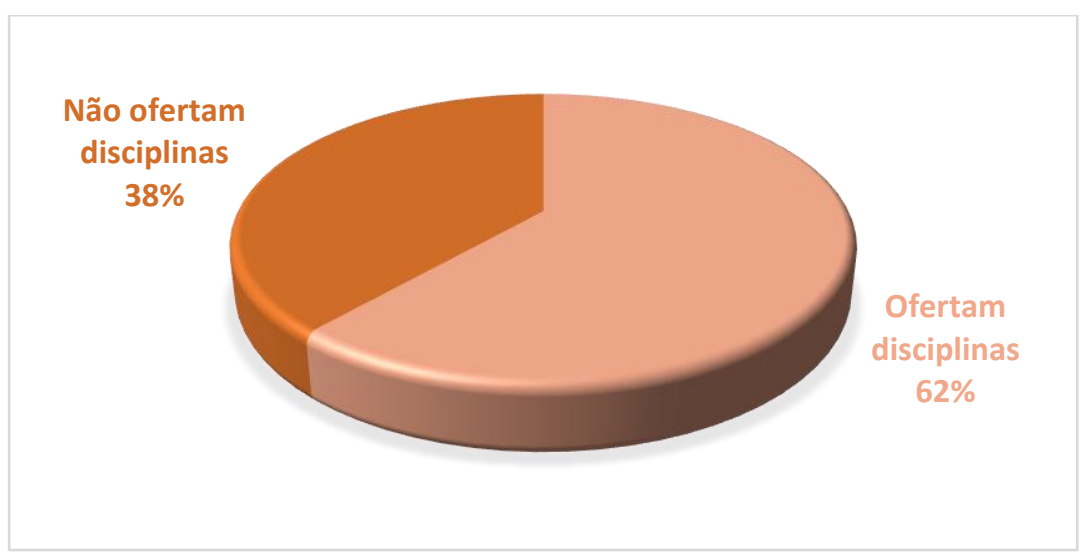

Gráfico 2: Percentual de cursos que ofertam ou não disciplina sobre a História e Cultura Afro-Brasileira - Região Nordeste

Fonte: Elaborado pelas autoras com base nas matrizes das IES analisadas

26 Perfil do Curso Licenciatura em Artes Visuais. Disponível em: http://cev.urca.br/cev/vestibular/pdf/20172/PERFIL_Cursos_ATUAL.pdf. Acesso em: 18 mai. 2021.

27 Projeto Pedagógico do Curso Licenciatura em Artes Visuais criado em 2019. Disponível em: <https://sigaa.ufrn.br/sigaa/verProducao?idProducao=7833568\&\&key=b85a607a0101fcb9db02d2271ae6de7d $>$. Acesso em: 18 mai. 2021.

28 Projeto Pedagógico do Curso Licenciatura em Artes Visuais criado em 2019. Disponível em: https://sigarq.ufpb.br/arquivos/201817614224e7743986e4ae375fee8e/PPC_Artes_Visuais.pdf. Acesso em: 18 mai. 2021. 29 Componente Curricular. Disponível em: <https://www.ufpe.br/documents/484600/0/artes_visuais_perfil_ 00114.pdf/f709d89f-3da4-4053-bb47-3a8dd2e97393>. Acesso em: 07 out. 2019.

30 Estrutura Curricular criada em 2011 do Curso Licenciatura em Artes Visuais. Disponível em: <https://www.sigaa.ufs.br/sigaa/link/public/curso/curriculo/625>. Acesso em: 07 out. 2019.

31 Relatório Perfil Curricular criado em 2016. Disponível em: <http://portais.univasf.edu.br/ estudante/informacoes-ao-estudante/cursos/graduacao/arquivos/artes.pdf >. Acesso em: 17 out. 2019.

32 Lista de disciplinas criada em 2009 do curso Licenciatura em desenho e plástica.

33 Projeto Pedagógico de curso Licenciatura Interdisciplinar em Artes e suas Tecnologias criado em 2016. Disponível em: <https://ufsb.edu.br/ihac/images/arquivos/PPC/PPC-LI-Artes-2016.pdf>. Acesso em: 07 out. 2019.

34 Componentes curriculares do Curso Licenciatura em Artes Visuais. Disponível em: https://sig.ufob.edu.br/sigaa/public/curso/curriculo.jsf. Acesso em: 18 mai. 2021. 
A partir dos dados apresentados, constatamos que os cursos da Região Nordeste oferecem uma quantidade maior de disciplinas que atentam para a diversidade étnicoracial do que os cursos da Região Sul. Na Região Nordeste, 62\% (oito das 13 IES analisadas) dos cursos ofertam disciplinas sobre a temática da história e cultura afrobrasileira, enquanto na Região Sul o percentual é de 43\% (seis das 14 IES analisadas).

Outro dado encontrado foi que nas IES analisadas na Região Nordeste, tal como na Região Sul, há disciplinas que em seu título não constam explicitamente a história e a cultura afro-brasileira, mas que as apresentam em suas ementas, como na UFRN:

PERSPECTIVAS EM ARTE CONTEMPORÂNEA. Seminários e pesquisa sobre questões relativas à igualdade de gênero, direitos humanos, inclusão social, étnicorracial, geracional e religiosa, relacionados à produção em Arte Contemporânea. Influências na arte de vertentes afro-ameríndias e indígenas.

HISTÓRIA DA ARTE NO BRASIL. Arte indígena. Arte no período colonial e no Império. Modernismo e arte contemporânea. Arte afro-brasileira. Arte e política: etnias, gêneros, meio ambiente.

FOTOGRAFIA, RETRATOS E IDENTIDADES CULTURAIS. Fundamentos da fotografia humana e do retrato. Observação das identidades culturais e sociais através das imagens. A cultura indígena e afro-brasileira (UFRN, 2015, p. 186-302, grifo das autoras).

Vemos, portanto, que alguns cursos de Licenciaturas em Artes Visuais, tanto na Região Sul como no Nordeste, apresentam disciplinas que incluem a história e a cultura afro-brasileira e/ou indígenas em suas ementas e bibliografias, mesmo que o título não deixe explícito. Este artigo, porém, restringe-se apenas à análise das disciplinas intituladas com a temática pesquisada.

\section{Análises das ementas das disciplinas sobre a história e a cultura afro-brasileira ofertadas nos cursos de Artes Visuais}

Após observarmos a quantidade de disciplinas específicas sobre a temática da história e da cultura afro-brasileira, selecionamos as ementas de tais disciplinas de todos os cursos das duas regiões brasileiras para buscar semelhanças e diferenças. Na Região Sul, seis das 14 IES analisadas ofertam pelo menos uma disciplina, a saber: UNICENTRO, UEL, IFPR, UDESC, UFRGS e UFPEL e, na Região Nordeste, oito IES, das 13 analisadas ofertam disciplinas específicas sobre o tema, a saber: UFMA, IFMA, UFPI, URCA, UFRN, UFPE, UFSB e UFBO. Na sequência podemos observar (Tabelas 3 e 4) o ementário das disciplinas ofertadas por essas IES. 


\begin{tabular}{|c|c|c|}
\hline IES & Disciplina & Ementa \\
\hline UNICENTRO & $\begin{array}{l}\text { Arte Africana } \\
\text { e Afro- } \\
\text { Brasileira }\end{array}$ & $\begin{array}{l}\text { As diversas manifestações artísticas dos povos } \\
\text { africanos e dos afro-brasileiros e seus contextos } \\
\text { culturais e históricos. }\end{array}$ \\
\hline UEL & $\begin{array}{l}\text { História da } \\
\text { Arte Africana } \\
\text { e Afro- } \\
\text { Brasileira }\end{array}$ & $\begin{array}{l}\text { Estudo da produção cultural e artística africana e afro- } \\
\text { brasileira. Arte tradicional africana. As culturas } \\
\text { africanas transplantadas para o Brasil. O artista negro } \\
\text { na produção brasileira. A arte contemporânea } \\
\text { africana e arte contemporânea afro-brasileira. }\end{array}$ \\
\hline IFPR & $\begin{array}{lr}\text { História } & \text { e } \\
\text { Cultura Afro } \\
\text { Brasileira e } \\
\text { Indígena }\end{array}$ & $\begin{array}{l}\text { O estudo da história da África e dos Africanos, a luta } \\
\text { dos negros e indígenas no Brasil, a cultura negra } \\
\text { brasileira e a indígena na formação da sociedade } \\
\text { nacional, resgatando a contribuição do povo negro e } \\
\text { indígena nas áreas social, econômica e política } \\
\text { pertinentes à história do Brasil. }\end{array}$ \\
\hline UDESC & $\begin{array}{l}\text { Arte africana } \\
\text { e afro- } \\
\text { descendente }\end{array}$ & $\begin{array}{l}\text { Continente africano e diversidade cultural. África } \\
\text { Magrebe e Subsaariana. A divisão geopolítica a partir } \\
\text { dos processos de colonização e descolonização do } \\
\text { continente africano. Tradição e modernidade na arte } \\
\text { africana e afro-descendente. Fronteiras e } \\
\text { contaminações da arte africana e da arte européia. } \\
\text { Cultura e identidade na expressão artística africana e } \\
\text { afro-descendente. Novas mídias e sua relação na arte } \\
\text { africana contemporânea. Inserção das artes africanas } \\
\text { e afro-descentedes no circuito contemporâneo das } \\
\text { artes plásticas - Les Magiciens de la Terre, África } \\
\text { Remix, Museu Afro-Brasil de São Paulo. }\end{array}$ \\
\hline \multirow[t]{3}{*}{ UFRGS } & $\begin{array}{l}\text { Culturas } \\
\text { Ameríndias e } \\
\text { Afro- } \\
\text { brasileiras no } \\
\text { ensino de } \\
\text { arte }\end{array}$ & $\begin{array}{l}\text { Conhecimento dos principais aspectos das culturas } \\
\text { afrodescendentes e ameríndias com vistas à } \\
\text { valorização em projetos de ensino ligados ao } \\
\text { componente curricular Arte. Apresentação das } \\
\text { matrizes brasileiras em suas relações políticas e } \\
\text { sociais contemporâneas, nos livros didáticos e nas } \\
\text { comunidades indígenas e quilombolas. }\end{array}$ \\
\hline & $\begin{array}{ll}\text { Educação e } \\
\text { relações } \\
\text { étnico- } \\
\text { raciais }\end{array}$ & Não encontrado \\
\hline & $\begin{array}{l}\text { Povos } \\
\text { indígenas } \\
\text { educação e } \\
\text { escola }\end{array}$ & Não encontrado \\
\hline UFPEL & $\begin{array}{l}\text { Arte } \mathrm{e} \\
\text { Cultura Afro- } \\
\text { brasileira }\end{array}$ & $\begin{array}{l}\text { O estudo das manifestações artístico-culturais afro- } \\
\text { brasileira do século XIX aos dias atuais. Conteúdo } \\
\text { programático: O carnaval - a evolução e suas } \\
\text { conexões com as tecnologias; O ensino formal e a } \\
\text { cultura popular urbana; Educação formal e } \\
\text { Identidade; Arte x religião; Arte, cultura e mídia; Arte } \\
\text { e ciência; Mestres populares e trabalhos sociais } \\
\text { dentro da escola e em comunidades; O folclore } \\
\text { brasileiro e suas diversas manifestações culturais; O } \\
\text { rap e o funk na socialização da juventude; O hip-hop }\end{array}$ \\
\hline
\end{tabular}




\begin{tabular}{|l|l|}
\hline & $\begin{array}{l}\text { e suas conexões; O grafite - história e prática para } \\
\text { uma reflexão política e social. }\end{array}$ \\
\hline
\end{tabular}

Tabela 3: Ementas das disciplinas que ofertam disciplinas diretamente relacionadas à História e Cultura Afro-brasileira na Região Sul

Fonte: Tabela elaborada pelas autoras com base nas matrizes das IES analisadas

Na sequência, apresentamos as ementas das disciplinas nas IES selecionadas que indicaram relações com a história e a cultura afro-brasileira na Região Nordeste, para posteriormente realizarmos as considerações e possíveis comparações entre as ementas supracitadas, relativas aos cursos de Licenciatura em Artes Visuais na Região Sul.

\begin{tabular}{|c|c|c|}
\hline IES & Disciplina & Ementa \\
\hline UFMA & $\begin{array}{l}\text { Arte Indígena, } \\
\text { Africana e Afro- } \\
\text { Brasileira. }\end{array}$ & $\begin{array}{l}\text { Estudos da arte dos povos indígenas do Brasil e do } \\
\text { Maranhão inserida no seu contexto cultural e suas } \\
\text { influências, observando a distinção entre arte dos } \\
\text { rituais e arte inserida no cotidiano, bem como suas } \\
\text { técnicas e materiais expressivos. Estudos da arte } \\
\text { africana inserida no seu contexto cultural, observando } \\
\text { a relação arte e religião no âmbito dos rituais, e sua } \\
\text { referência na arte afro-brasileira, buscando perceber o } \\
\text { espaço das artes visuais na cultura afro-brasileira local. }\end{array}$ \\
\hline IFMA & $\begin{array}{l}\text { História e Cultura } \\
\text { Africana e Afro- } \\
\text { brasileira }\end{array}$ & $\begin{array}{l}\text { Pretende fornecer aos alunos conteúdos conceituais } \\
\text { capazes de referenciar o entendimento das } \\
\text { contribuições culturais africanas e afro-brasileiras. } \\
\text { Buscar-se-á analisar as sociedades africanas nos } \\
\text { séculos XVI e XVII, a África na formação do mundo } \\
\text { atlântico, dinâmicas do tráfico: as nações africanas na } \\
\text { América portuguesa, resistência negra: revoltas, } \\
\text { quilombos e ações cotidianas na luta pela liberdade; } \\
\text { bem como a religiosidade, o sincretismo e os } \\
\text { afrodescendentes na sociedade brasileira do pós- } \\
\text { abolição. }\end{array}$ \\
\hline UFPI & $\begin{array}{l}\text { História e Cultura } \\
\text { Africana e Afro- } \\
\text { brasileira }\end{array}$ & Não encontrado \\
\hline URCA & $\begin{array}{l}\text { História e Cultura } \\
\text { Africana e Afro- } \\
\text { brasileira }\end{array}$ & $\begin{array}{l}\text { Compreensão das manifestações artísticas africanas e } \\
\text { sua inserção na História da Arte brasileira. }\end{array}$ \\
\hline UFRN & $\begin{array}{l}\text { Direitos humanos, } \\
\text { diversidade } \\
\text { cultural e relações } \\
\text { étnico-raciais }\end{array}$ & $\begin{array}{l}\text { Etnocentrismo, Discriminação, Preconceito } \\
\text { Relativismo cultural. Diversidade, Alteridade e } \\
\text { Processos identitários, Etnicidade, Relações étnico- } \\
\text { raciais (povos indígenas, quilombolas, ciganos, grupos } \\
\text { étnicos, etc.) e de gênero/sexualidade. Cidadania, } \\
\text { Justiça e Protagonismo social. Antropologia e Direitos } \\
\text { Humanos. Educação e Práticas inclusivas. }\end{array}$ \\
\hline UFPE & $\begin{array}{l}\text { Arte e diversidade } \\
\text { étnico-cultural }\end{array}$ & $\begin{array}{l}\text { Estudo da arte no Brasil abrangendo diversos contextos } \\
\text { e práticas étnico-culturais, especialmente os de cultura } \\
\text { indígena, afro-brasileira e popular, envolvendo }\end{array}$ \\
\hline
\end{tabular}




\begin{tabular}{|c|c|c|}
\hline & & $\begin{array}{l}\text { questões relacionadas às suas dinâmicas, hibridizações } \\
\text { e interculturalidade. }\end{array}$ \\
\hline \multirow[t]{2}{*}{ UFSB } & $\begin{array}{lr}\text { Educação } & \text { e } \\
\text { Relações } & \text { Ético- } \\
\text { Raciais } & \end{array}$ & $\begin{array}{l}\text { Plano nacional de implantação das diretrizes } \\
\text { curriculares para as relações étnico raciais e história } \\
\text { das culturas indígenas, africanas e afro-brasileiras. } \\
\text { Debate sobre as leis } 10639 / 2003 \text { e } 11645 / 2008 \text {; } \\
\text { políticas públicas e educação. }\end{array}$ \\
\hline & $\begin{array}{l}\text { Estéticas } \\
\text { negrodescendentes }\end{array}$ & $\begin{array}{l}\text { Estudo das culturas africanas, diaspóricas e do negro } \\
\text { no Brasil. Sistema de arte fundado em práticas } \\
\text { culturais negrodescendentes no Brasil. Culturas } \\
\text { negras, sistemas de arte ocidentais e autóctones - } \\
\text { encontros/confrontos e desdobramentos artísticos. } \\
\text { Leituras e releituras da historiografia produzida pelo } \\
\text { eurocentrismo; dos Estudos Colonialistas aos Estudos } \\
\text { Culturais. 'Afro-brasilidade' como unidade cultural - da } \\
\text { marginalização eurocêntrica à conjuntura política atual. } \\
\text { Arte e cultura: alteridade nas relações entre as } \\
\text { matrizes afrodescendentes e outras matrizes culturais } \\
\text { presentes no Brasil. }\end{array}$ \\
\hline UFBO & $\begin{array}{l}\text { História e Cultura } \\
\text { Indígena e Afro- } \\
\text { brasileira }\end{array}$ & $\begin{array}{l}\text { Estudos sobre a cultura africana e suas dimensões } \\
\text { artísticas, simbólicas e sociais. Análise da produção } \\
\text { imagética relacionada às diásporas no ocidente, } \\
\text { sobretudo a migração das culturas africanas para o } \\
\text { Brasil durante os séculos, refletindo o caráter } \\
\text { ideológico e as consequências identitárias desses } \\
\text { processos. Modos de produção artística, os sistemas da } \\
\text { arte africana e a difusão dessas imagens por diversos } \\
\text { meios. Estudo do transcurso histórico e cultural das } \\
\text { sociedades indígenas no atual território brasileiro, do } \\
\text { período Paleoíndio até os tempos atuais. O patrimônio } \\
\text { da cultura material e imaterial indígena. }\end{array}$ \\
\hline
\end{tabular}

Tabela 4: Ementas das disciplinas que ofertam disciplinas diretamente relacionadas à História e Cultura Afro-brasileira na Região Nordeste

Fonte: Tabela elaborado pelas autoras com base nas matrizes das IES analisadas

Um ponto que pudemos analisar pelas ementas é se os cursos abordam questões regionais dentro das disciplinas analisadas. Percebemos que nas Regiões Nordeste e Sul, o único curso que deixa explícito que abarca a cultura afro-brasileira local é o da UFMA. Os outros trabalham com a cultura afro-brasileira de uma forma ampla, considerando o Brasil como um todo. Essa similaridade existente nos cursos de Licenciatura em Artes Visuais da Região Sul e Nordeste, tem a ver com o que Fonseca da Silva, Alvarenga e Bellan (2018) concluíram a partir de pesquisas acerca das Licenciaturas em Artes Visuais da Região Sul e Norte: essa homogeneização é fruto da legislação vigente, em função de políticas públicas neoliberais, implantadas a partir de 1990 na América Latina. Para elas, há pouco espaço para aspectos culturais regionais, fortalecendo, desse modo, as relações de uniformização da atuação docente, a precarização do professor e a paulatina perda de seu papel como transformador intelectual. 
Outro dado que podemos salientar é se a disciplina com a temática afro-brasileira divide sua carga horária com a temática indígena ou se o curso separa essas culturas. $\mathrm{Na}$ Região Nordeste, quatro cursos (UFBO, UFPE, UFRN, UFMA) ministram essas duas culturas juntas, três cursos (URCA, UFPI, IFMA) separam e o curso da UFSB tem uma disciplina separada e outra que compartilha com a temática indígena. Já na Região Sul, apenas duas (UFRGS ${ }^{35}$, IFPR) ministram a temática afro-brasileira juntamente com a indígena e em quatro (UFPEL, UDESC, UEL, UNICENTRO) há uma disciplina específica para a cultura afrobrasileira. Nosso receio, ao unir duas culturas tão distintas e complexas numa única disciplina, é se o professor é qualificado para ministrar as duas ou se ele vai salientar uma em detrimento da outra.

Outro ponto que verificamos é se a disciplina é mais voltada para os aspectos históricos, artísticos ou pedagógicos. As ementas e os títulos das disciplinas nos mostram que na Região Nordeste duas IES (IFMA, UFPI) abarcam mais os aspectos históricos e culturais; três (UFMA; URCA; UFPE) abrangem mais os aspectos artísticos e culturais; a UFRN abrange em sua maioria questões pedagógicas e dos direitos humanos; a UFBO abre tanto para os aspectos históricos, artísticos e culturais e a UFSB como tem duas disciplinas, uma abarca mais as questões pedagógicas e a outra as artísticas e culturais. Já na Região Sul: três (UEL; UDESC; UFPEL) abrangem mais os aspectos artísticos e culturais; o IFPR abarca mais os aspectos históricos e culturais; a UFRGS abrange em sua maioria questões pedagógicas e a UNICENTRO abre tanto para os aspectos históricos, como artísticos e culturais.

Vemos, portanto, que, tal como apresentado nas Tabelas 3 e 4, as ementas das disciplinas que abordam a temática da história e cultura afro-brasileira, nas duas regiões analisadas, revelam que não há uma homogeneização em ministrar esses conteúdos, pois cada universidade tem liberdade para fazer suas escolhas e isso ocorre a partir da visão e da missão de cada curso.

Fica a pergunta: essas disciplinas foram inseridas no currículo apenas para cumprir um 'protocolo' ou realmente estão contribuindo para a melhoria das relações raciais no Brasil? Acreditamos que novas pesquisas possam ser realizadas para responder essa questão, inclusive abrangendo entrevistas com professores formadores dessas universidades que lecionam tais disciplinas, assim como com os coordenadores desses cursos para verificar como eles compreendem essas disciplinas no currículo dos cursos de Licenciatura em Artes Visuais e suas possíveis repercussões.

\footnotetext{
35 Pelos títulos das três (3) disciplinas ofertadas por essa IES, todas indicam que a temática da história e cultura afro-brasileira será tratada de modo conjunto com a indígena.
} 


\section{Considerações finais}

A partir do exposto e tendo como referência a análise das matrizes curriculares dos 27 cursos de Licenciatura em Artes Visuais, presenciais, públicos, ofertados nas Regiões Nordeste (13) e Sul (14), constatou-se a presença da disciplina que aborda o tema da história e da cultura afro-brasileira de 'modo específico' em oito cursos da Região Nordeste e em seis cursos na Região Sul, totalizando 14 cursos. Dos 27 pesquisados, a Região Sul teve o menor percentual (43\%) de IES que ofertam as disciplinas que abordam a temática e a Região Nordeste apresentou um percentual maior (62\%).

Além das disciplinas específicas, também encontramos o tema pesquisado em outras disciplinas. Há IES nas duas regiões que contemplam de modo secundário a temática, visto que o assunto aparece de modo diluído em outras disciplinas do currículo, principalmente nas disciplinas de História da Arte no Brasil e em disciplinas de cunho pedagógico e não como disciplina específica. Sendo assim, consideramos que, nesse caso, o grau de aprofundamento do tema pode ser menor.

Todavia, tendo por base os dados apresentados por Silva (2012) sobre o pequeno número de cursos de Licenciatura em Artes Visuais que ofertava disciplinas sobre a temática em pauta, considerando o tempo de implementação da Lei 10.639/2003 e da Lei no $11.645 / 2008$, vemos que, a partir do recorte que fizemos, aproximadamente $50 \%$ dos cursos ofertam disciplinas de modo específico em suas matrizes curriculares. Acreditamos que já era momento de todos os cursos terem os conteúdos étnico-raciais inseridos em seus currículos, mas ainda há muitos desafios pela frente até vermos essa lei sendo contemplada em todas as regiões do Brasil: um deles é fazer com que todos os envolvidos na elaboração do Projeto Político do Curso, como os gestores, coordenadores e professores, tenham a clareza da importância desses conteúdos para a formação do indivíduo; outro desafio é efetivar profissionais qualificados, por meio de concursos públicos para ministrar essas disciplinas dentro dos cursos.

Além disso, podemos considerar que há uma diversidade na abordagem das disciplinas relacionadas à história e à cultura afro-brasileira, sendo que, por vezes, o peso do conteúdo previsto nas ementas recai sobre o aspecto pedagógico, como pudemos observar no curso da UFRGS, que valoriza aspectos das culturas afrodescendentes e ameríndias em projetos de ensino ligados ao componente curricular Arte e apresenta as relações políticas e sociais contemporâneas nos livros didáticos e nas comunidades indígenas e quilombolas. Outras vezes, o conteúdo recai sobre o aspecto histórico, como podemos perceber na ementa do curso do IFMA, que analisa as sociedades africanas nos séculos XVI e XVII, a África na formação do mundo atlântico, as dinâmicas do tráfico, a resistência negra, como revoltas, quilombos e ações cotidianas na luta pela liberdade e os 
afrodescendentes na sociedade brasileira do pós-abolição ou, ainda, recai na pauta dos direitos humanos, como é o caso do curso da UFRN, que discute sobre etnocentrismo, discriminação, preconceito, relativismo cultural, diversidade, alteridade, processos identitários, etnicidade, relações étnico-raciais, gênero/sexualidade, cidadania, justiça, protagonismo social e práticas inclusivas. Mas, na maioria das vezes, o conteúdo está centrado no viés artístico/cultural, como no caso do curso da UEL, que estuda a produção cultural e artística africana e afro-brasileira, a arte tradicional africana, as culturas africanas transplantadas para o Brasil, o artista negro na produção brasileira e a arte contemporânea africana e afro-brasileira. Em algumas ementas, esses quatro elementos (histórico, pedagógico, direitos humanos e viés artístico/cultural) são contemplados. Consideramos que a parte artística deva ser realçada, mas não em detrimento dos aspectos históricos e pedagógicos, visto que os cursos são específicos de Artes, no caso licenciaturas em Artes Visuais.

Ao verificarmos se a disciplina com a temática afro-brasileira divide sua carga horária com a temática indígena, inferimos que quatro das IES da Região do Nordeste e duas da Região Sul ministram as duas culturas juntas. As outras oito IES separam em disciplinas diferentes. Tal fato pode estar relacionado à própria Lei no 11.645/2008 que aborda a necessidade das duas temáticas serem contempladas no ensino de arte na escola. Mas, por meio dessa junção, pode haver uma mistura de culturas muito distintas, assim como a prevalência de uma sobre a outra conforme a abordagem por parte do professor formador e seu conhecimento sobre os assuntos.

Analisando as ementas das disciplinas que abordam especificamente a história e a cultura afro-brasileira, percebemos que apenas um curso da Região Nordeste aborda questões regionais dentro dessas disciplinas. Todas as outras abrangem a cultura afrobrasileira como homogênea dentro do Brasil, não especificando as diferenças e as peculiaridades de cada região.

Considerando a análise em cursos de Artes Visuais e a arte como produção humana, conferimos a importância de se trabalhar com produções e manifestações artísticas afrobrasileiras. Dessa forma, averiguamos se a abordagem das disciplinas estava direcionada para uma visão histórica, artística ou pedagógica. Constatamos que a maioria (oito de 14 IES) abarca aspectos artísticos da cultura afro-brasileira, estando de acordo com nossas expectativas, pois para nós a arte possui a capacidade de provocar o pensamento, permitindo realizar uma reflexão histórica e social do contexto. Assim, com o conhecimento da arte e da cultura afro-brasileira, o ser humano tem a possibilidade de criar uma consciência artística a fim de refletir e transformar a realidade. 


\section{Referências}

ALVARENGA, V. M. Formação inicial do professor de Artes Visuais: reflexões sobre os cursos de licenciatura no Estado do Paraná. Dissertação (Mestrado em Artes Visuais) Programa de Pós-Graduação em Artes Visuais, UDESC, 2015.

BRASIL. Presidência da República. Lei no 9.394, de 20 de dezembro de 1996. Estabelece as diretrizes e bases da educação nacional. Brasília, [2009]. Disponível em: <http://www.planalto.gov.br/ccivil_03/leis/l9394.htm>. Acesso em: 15 abr. 2021.

BRASIL. Lei no 10.639, de 9 de janeiro de 2003. Altera a Lei no 9.394 , de 20 de dezembro de 1996, que estabelece as diretrizes e bases da educação nacional, para incluir no currículo oficial da Rede de Ensino a obrigatoriedade da temática "História e Cultura Afro-Brasileira", e dá outras providências. Diário Oficial [da] República Federativa do Brasil. Brasília, DF, 9 jan. 2003.2 Disponível em: <http://www.planalto.gov.br/ccivil_03/leis/2003/L10.639.htm>. Acesso em: 06 out. 2019.

BRASIL. Presidência da República. Lei no 11.645, de 10 de março de 2008. Lei para incluir no currículo oficial da rede de ensino a obrigatoriedade da temática "História e Cultura Afro-Brasileira e Indígena". Disponível "em: <http://www.planalto.gov.br/ccivil_03/_ato2007-2010/2008/lei/l11645.htm>. Acesso em: 15 maio 2017.

BRASIL. Ministério da Educação. Diretrizes curriculares nacionais para a educação das relações Étnico-raciais e para o ensino de história e cultura afro-brasileira e africana. Brasília: MEC, 2004.

BRASIL. Ministério da Educação. Resolução no 2, de $1^{\circ}$ de julho de 2015. Define as Diretrizes Curriculares Nacionais para a Formação Inicial em Nível Superior e para a Formação Continuada. Brasília, 2015. Disponível em: <http://portal.mec.gov.br/index.php?option=com_docman\&view=download\&alias $=1367$ 31-rcp002-15-1\&category_slug=dezembro-2019-pdf\&Itemid=30192>. Acesso em: 15 abr. 2021.

BRASIL. Decreto $\mathrm{n}^{\circ} \mathbf{1 . 3 3 1}$, de 17 de fevereiro de 1854. Aprova o regulamento para a reforma do ensino primário e secundário do Município da Corte. 1854. Disponível em: <http://ciespi.org.br/media/decreto_1331_17_fev_1854.pdf>. Acesso em: 22 abr. 2021.

BRASIL. Decreto no. 6.096, de 24 de abril de 2007. Institui o Programa de Apoio a Planos de Reestruturação e Expansão das Universidades Federais - REUNI. Brasília, CN, 2007. Disponível em: <http://www.planalto.gov.br/ccivil_03/_Ato2007-2010/2007/Decreto/D6096.htm>. Acesso em: 22 abr. 2021.

BRASIL. Decreto Federal no 7.031, de 06 de setembro de 1878 . Estabelecia que os negros só podiam estudar no período noturno. Diário Oficial da União. Brasília, 1878. Disponível em: <http://www2.camara.gov.br/legin/fed/decret/1824-1899/decreto-7031a-6-setembro-1878-548011-publicacaooriginal-62957-pe.html>. Acesso em: 22 abr. 2021.

FONSECA DA SILVA, M. C.; ALVARENGA, V. M. de; BELLAN, C. C. Observatório da formação de professores de Artes Visuais: uma análise à luz das políticas vigentes. In: Revista GEARTE, Porto Alegre, v. 5, n. 2, p. 272-288, maio/ago. 2018. Disponível em: <http://dx.doi.org/10.22456/2357-9854.84680>. Acesso em: 06 out. 2019. 
MUNANGA, K. Arte afro-brasileira: o que é afinal? In: Revista Paralaxe. v. 6, n. 1, 2019. Disponível em: <https://revistas.pucsp.br/paralaxe/article/viewFile/ 46601/30949>. Acesso em: 16 abr. 2021.

PERINI, J. A. Arte e Cultura Africana, Afro-brasileira e Indígena nas Licenciaturas em Artes Visuais do Maranhão. p. 276. Tese (Doutorado em Artes Visuais). Universidade do Estado de Santa Catarina, Centro de Artes. Doutorado em Artes Visuais, Florianópolis, $2020 . \quad$ Disponível em: <https://sistemabu.udesc.br/pergamumweb/vinculos/000081/00008197.pdf>. Acesso em: 22 abr. 2021

PERINI, J. A. Vale do Ribeira: uma contribuição das redes virtuais quilombolas para a formação de professores de Artes Visuais na perspectiva da Lei 10.639/2003. 2012. Dissertação (Mestrado em Artes Visuais). Universidade do Estado de Santa Catarina, Centro de Artes, Florianópolis, 2012. Disponível em: <http://www.tede. udesc.br/bitstream/handle/675/1/Janine\%20Alessandra\%20Perini.pdf>. Acesso em: 01 out. 2019.

SILVA, B. C. C. da. Levantamento e análise de informações sobre o desenvolvimento da temática "História e Cultura indígena" nos cursos de licenciatura de instituições públicas e privadas. Ministério de Educação - Conselho Nacional de $2012 . \quad$ Disponível em: <http://portal.mec.gov.br/index.php?option=com_docman\&view=download\&alias $=1394$ 0-produto-1-historia-cultura-povos-indiginas-pdf\&Itemid=30192>. Acesso em: 18 jan. 2021.

UNIVERSIDADE ESTADUAL DE PONTA GROSSA. Curso de Licenciatura em Artes Visuais da UEPG. Ponta Grossa, [s/d]. Disponível em: <https://www.uepg.br/catalogo/cursos/2016/artesvisuais.pdf>. Acesso em: 21 abr. 2021.

UNIVERSIDADE FEDERAL DO RIO GRANDE DO NORTE. Curso de Licenciatura em Artes Visuais da UFRN. Natal, [s/d]. Disponível em: <https://sigaa.ufrn.br/sigaa/verProducao?idProducao $=7833568 \& \&$ key $=$ b85a607a0101fc b9db02d2271ae6de7d>. Acesso em: 18 mai. 2021.

UNIVERSIDADE ESTADUAL DO PARANÁ II (FAP). Curso de Licenciatura em Artes Visuais da UNESPAR II (FAP). Curitiba, [s/d]. Disponível em: < http://webcache.googleusercontent.com/search?q=cache:jKZqO36CWcY]:fap.curitiba2.u nespar.edu.br/assuntos/graduacao/Matriz_curricular_Artes_visuais_2017_1.pdf $+\& c d=2 \&$ $\mathrm{hl}=\mathrm{pt}-\mathrm{BR} \& \mathrm{ct}=\mathrm{clnk} \& \mathrm{gl}=\mathrm{br}>$. Acesso em: 10 mai. 2021.

VÁZQUEZ, A. S. As ideias estéticas de Marx. Tradução de Carlos Nelson Coutinho. 3. ed. São Paulo: Expressão Popular, 2011.

i Professora de Artes Visuais da Universidade Federal do Maranhão, Campus São Bernardo. Doutora em Artes Visuais pelo PPGAV/ UDESC. Possui Mestrado em "Artes Visuais", pela UDESC (2012), especialização em "O Ensino da Arte: Fundamentos Estéticos e Metodológicos" pela UNIVILLE (1998), especialização em "Arteterapia" pelo INPG (2007), graduação em Educação Artística pela UNIVILLE (1998) e graduação em Licenciatura em Pedagogia pela UNIFACVEST (2020). Participa dos grupos de pesquisa: Educação, Arte e Inclusão, UDESC e Grupo de Estudos e Pesquisas Interdisciplinares sobre as Cidades CITADINO, UFMA. 
ii Doutora e Mestra em Artes Visuais (UDESC). Graduada em Artes Visuais (Licenciatura e Bacharelado/UFPR). Professora de Artes Visuais na UNINTER e na Secretaria de Estado da Educação (SEED/PR). Integrante do grupo de pesquisa Educação, Artes e Inclusão, da UDESC.

Como citar esse artigo:

PERINI, Janine Alessandra; ALVARENGA, Valéria Metroski. História e cultura afro-brasileira nos cursos de Licenciatura em Artes Visuais do nordeste e sul do Brasil. Revista Digital do LAV, Santa Maria: UFSM, v. 14, n. 2, p. 337-358, mai./ago. 2021. 